\title{
Una carta de pésame en arameo de Samuel ha-Naguid
}

\author{
Amparo Alba Cecilia y Juan José Alarcón Sainz * \\ Universidad Complutense, Madrid
}

\section{LA ACADEMIA RABÍNICA DE QAYRAWÁN}

Entre la abundante correspondencia que, en razón de su cargo y condición, mantuvo Samuel ibn Nagrella ${ }^{1}$ con destacados sabios y eruditos de su época, se encuentra esta carta de pésame cuya traducción y estudio ofrecemos. La carta, escrita en arameo, está dirigida a Ḥananel ben Ḥušiel, hijo de R. Ḥušiel, el fundador de la academia rabínica de Qayrawán, y su sucesor al frente de la misma.

El establecimiento de rutas comerciales marítimas entre todos los países que formaban parte del imperio islámico favoreció el desarrollo de la actividad comercial de los judíos, que llegaron a convertirse en «los grandes comerciantes internacionales» de la Edad Media ${ }^{2}$, como atestiguan numerosos responsa de los gaones, escritos entre los siglos IX y XI. Esto favoreció el asentamiento de nuevas comunidades judías, especialmente en enclaves cercanos a la costa, y el consiguiente enriquecimiento, también a nivel cultural, de dichas comunidades.

La comunidad judía de Qayrawán, se vio, según todos los indicios, beneficiada por estas circunstancias. En el famoso relato de «los cuatro cautivos» del Sefer ha-Qabbalah ${ }^{3}$, ideado, a todas luces, para fundamentar la autoridad

* aalba@filol.ucm.es; jjalarco@filol.ucm.es

${ }^{1}$ Un estudio sobre la vida y obra de este autor, así como una completa bibliografía, se encuentra en A. Sáenz-Badillos y J. Targarona Borrás, Semu'el ha-Naguid. Poemas. I. Desde el campo de Batalla. Granada 1038-1056. Edición del texto hebreo, introducción, traducción y notas (Granada 1990); y en A. SÁenz-Badillos y J. Targarona Borrás, Semu'el ha-Naguid. Poemas. II. En la Corte de Granada. Edición del texto hebreo, introducción, traducción y notas (Granada 1998).

${ }^{2}$ H. H. Ben-SAsson, Historia del pueblo judío, vol. II: La Edad Media (Madrid 1988) pág. 470.

3 Abraham ibn Daud, Libro de la tradición (Sefer ha-Qabbalah). Introducción, traducción y notas por Lola FerRe (Barcelona 1990) pág. 84. 
rabínica de Sefarad y romper su dependencia de las academias babilónicas, aparece mencionado R. Ḥušiel ben Elḥanán, de cuyo rescate como cautivo de mar se hizo cargo la comunidad judía de Qayrawán, que le nombró su jefe espiritual. Dejando a un lado los detalles novelescos y legendarios que Abraham ibn Daud aporta en su obra, se puede afirmar que R. Hušiel llegó a Qayrawán procedente del sur de Italia (Bari) entre 960 y 990. En esa época, la comunidad judía de Qayrawán gozaba ya de una gran fama por el alto nivel que los estudios talmúdicos habían alcanzado; fue la cuna o el lugar de asentamiento de personajes de gran relieve intelectual, como Mar Ukbá ${ }^{4}$, Eldad ha-Daní ${ }^{5}$ o Isaac Israelí ${ }^{6}$ que contribuyeron al enriquecimiento cultural de la comunidad. Las relaciones de los jefes religiosos con las academias babilónicas de Sura y Pumbedita eran muy intensas y fluidas: R. Ya'acob ben Nissim ibn Šahín, líder espiritual de la comunidad de Qayrawán durante el último cuarto del siglo $\mathrm{X}$, era el representante oficial de la academia de Pumbedita para toda el África occidental y, quizás también, para España; fueron, precisamente, sus cuestiones acerca de la redacción de la Misná, la Tosefta y el Talmud, las que dieron lugar a la famosa epístola del gaón de Pumbedita R. Šerirá, Iggeret Rab Sherira Gaon ${ }^{7}$, un clásico de la historiografía judía. Ha quedado constancia, también, del gran aprecio en que, tanto R. Šerirá como su hijo, R. Ḥay ${ }^{8}$, el último gaón, tenían a Ya'acob.

A finales del siglo X, la llegada de Ḥušiel ben Elḥanán a Qayrawán marcó un punto de inflexión en los estudios talmúdicos: introdujo en su academia talmúdica un nuevo método de estudio caracterizado por la importancia que concedió al Talmud de Jerusalén y los midrašim halájicos como fuente para establecer la Halajá, aunque esto supusiera la existencia de contradicciones con el Talmud de Babilonia, como queda patente en la elegía contenida en

${ }^{4}$ Exilarca. Como consecuencia de una violenta disputa con el gaón de Pumbedita, R. Judá b. Samuel, por el reparto de los ingresos de la academia, fue condenado al destierro desde 909 a 916. En cumplimiento de este destierro, llegó a Qayrawán, donde fue recibido con todos los honores.

${ }^{5}$ En 880 el misterioso viajero judío Eldad ha-Daní, que se proclamaba descendiente de una de las diez tribus perdidas, se estableció en Qayrawán. Su presencia y conocimiento sirvieron de estímulo a los rabinos e intelectuales de la comunidad.

${ }^{6}$ El medico y filósofo Isaac Israelí se estableció, procedente de Egipto, en Qayrawán, donde ostentó el cargo de médico real desde 904. Entre sus numerosos discípulos destaca el astrónomo y físico Dunaš ibn Tamim. Israelí murió en Qayrawán en 932 o 942.

7 B. M. Lewin (ed.), Iggeret Rab Sherira Gaon, (Frankfurt am Main 1920; reimpr. Jerusalén 1972).

8 A. HaRKAVY, «Teshubot ha-geonim», Zakhar la-Rishonim 4 (1887) pág. 257.

Sefarad, vol. 67:2, diciembre-junio 2007, págs. 311-325. ISSN 0037-0894 
la carta, en los versos 17 y siguientes. La fama adquirida por la academia rabínica de R. Hušiel permitió su desvinculación de la dependencia que hasta entonces había tenido con las academias babilónicas, lo cual contribuyó en gran medida a la decadencia de dichas academias.

A su muerte, hacia 1027, le sucedió al frente de la academia de Qayrawán su hijo R. Ḥananel b. Hušiel quien, siguiendo el ejemplo de su padre, dio preferencia en sus comentarios al Talmud de Jerusalén, la Tosefta y los midrašim halájicos frente al Talmud de Babilonia. Murió Ḥananel en el año 1055 o 1056, y le sucedió en el cargo de jefe de la academia R. Nissim de Qayrawán ${ }^{9}$. Como dato curioso de la buena relación existente entre Samuel ha-Naguid y los miembros de la academia de Qayrawán, podemos mencionar que el primogénito y más querido de los hijos de Samuel ha-Naguid, Yehosef, se casó con la hija de R. Nissim de Qayrawán. ${ }^{10}$

Es, pues, en este contexto y con estos protagonistas, donde hay que situar nuestro texto, la carta de pésame compuesta por Samuel ha-Naguid para Hananel ben Ḥušiel por la muerte de su padre.

\section{LA CARTA DE PÉSAME}

Se trata de una composición escrita, en su totalidad, en arameo, con la única excepción del hebreo de algunas citas bíblicas; la carta tiene una extensión de unas cuarenta y cinco líneas ${ }^{11}$ en prosa rimada; hacia la mitad de la carta se incluye un poema monorrimo de 25 versos compuesto, también, en arameo ${ }^{12}$.

La prosa rimada, utilizada por los árabes ya desde época preislámica, fue la forma de expresión preferida por los escritores hispanohebreos para muchas de sus composiciones, especialmente, las epístolas. Frente a la prosa normal, utilizada principalmente para composiciones científicas (filosofía, medicina, astrología...), la prosa rimada, que consta de metro y rima, es considerada más digna y, aunque no llegue a alcanzar la perfección artística de la poesía, requiere, por

\footnotetext{
${ }^{9}$ Sobre su vida y obra, ver A. Alba, Midrás de los Diez Mandamientos y libro precioso de la salvación (Valencia 1990) págs. 103-109.

${ }^{10}$ IBN DAUD, Libro de la tradición, pág 94.

${ }^{11}$ Hemos seguido la edición de D. YARDEn, Divan Shmuel HaNaguid (The Collected Poetry of Samuel the Prince, 993-1056). Ben Tehilim (The Son of Psalms) (Jerusalem 1985) págs. 256260.

${ }^{12}$ Publicamos una versión al castellano de esta elegía en SÁEnz-Badillos y Targarona Borrás, Semu'el ha-Naguid. Poemas. II, págs. 125-127.
} 
parte del autor, de buenas dotes poéticas, del dominio de la lengua y de la técnica versificadora para obtener unos buenos resultados.

En la epístola, Samuel ha-Naguid alterna secuencias rimadas con otras sin rima o con rima anómala; se sirve abundantemente de elementos gramaticales muy frecuentes en la lengua aramea, como el artículo al final de la palabra, los plurales en «in» y los sufijos pronominales, para establecer la rima; esto, unido al hecho de la escasez de elementos nominales con rima consonántica, nos permite calificar la técnica poética de la epístola como de rima pobre ${ }^{13}$. El poema, por el contrario, muestra una gran perfección técnica; como corresponde a la estructura de la casida árabe clásica, no tiene división estrófica, presenta una rima común final consonántica en $\mid-y a^{\prime} /$ y utiliza el metro $h a-$ mahir --u-1---1--

Ibn Nagrella, como el resto de los poetas hispanohebreos, recurre en esta composición al denominado «estilo de mosaico», con la inserción de citas bíblicas que adapta a un nuevo contexto; sin embargo, al elegir la lengua aramea para su carta, el uso de citas bíblicas queda casi reducido a los textos arameos de la Biblia, mientras que hay una gran recurrencia de textos en arameo pertenecientes a la literatura rabínica, como el Targum, el Midrás y, sobre todo, como se podrá ir observando en las notas, el Talmud ${ }^{14}$. Gracias a esta concatenación de citas sacadas de su contexto y adaptadas a uno nuevo, el autor consigue elaborar una preciosa obra literaria, además de demostrar, sin lugar a dudas, su buena formación y dominio de todas las fuentes judías anteriormente mencionadas. ${ }^{15}$

\section{Análisis de la Carta}

La muerte de un ser querido o de un personaje destacado da pie a la expresión de duelo y consuelo que conocemos como «elegía». Los autores hispanohebreos cultivaron con profusión el género elegíaco y demostraron una gran maestría en las com-

\footnotetext{
${ }^{13}$ Según la denominación habitual, o aruz 'ober; ver, por ejemplo, O. Ducrot- T. Todorov, Diccionario enciclopédico de las ciencias del lenguaje (Buenos Aires 1975) y H. ZaFrani, Poésie juive en Occident musulman (Paris 1977).

${ }^{14}$ En ocasiones, tanto las citas bíblicas como las rabínicas son difíciles de rastrear, ya que el autor las inserta en versión aramea.

15 Para hacerse una idea del proceso de formación y los conocimientos adquiridos por Samuel ha-Naguid, se puede consultar Sáenz-Badillos y Targarona Borrás, Semu'el ha-Naguid. Poemas. I, págs. XI ss. 
posiciones de este tipo ${ }^{16}$, al que pertenecen algunos de los mejores poemas escritos en Sefarad.

Tanto la carta como el poema de Ibn Nagrella contienen los principales elementos que caracterizan a la elegía hispanohebrea: alabanza del muerto, expresión de duelo por el difunto, palabras de consuelo para sus deudos y reflexiones de tipo sapiencial sobre la vida y la muerte.

La carta va precedida de un título, en árabe y en hebreo, obra con toda seguridad de Yehosef, el hijo de Samuel ibn Nagrella, que precisa su contenido así como los nombres del destinatario y el remitente.

El cuerpo de la carta, que introduce y justifica el poema, comienza con una dedicatoria en la que el autor hace un elogio del destinatario, R. Hananel, lleno de referencias bíblicas y rabínicas. Sigue una alusión a un acontecimiento desdichado, como es la muerte de un ser excepcional, en la que el autor expresa, mediante el uso de hipérboles, el intenso dolor y la conmoción que esta desgracia ha causado, no sólo al hijo del difunto, sino también a toda la comunidad constituida por «los hijos de la Torá» e incluso «a todos los habitantes de la tierra» pues es bien sabido que «cuando muere un sabio, todos son sus parientes», por eso, las señales de luto son evidentes, y todo signo de lujo o belleza ha sido arrinconado: «la túnica de fiesta se ha ocultado de nuestra vista, se ha escondido la perla ...»

El «rescate del difunto» es un motivo que aparece con frecuencia en los poemas elegiacos: el poeta expresa su deseo de ponerse en lugar del difunto y rescatarle de su trágico destino ${ }^{17}$; aquí encontramos una variante del motivo: el estadista y jefe de su comunidad, Samuel ha-Naguid, manifiesta su intención de poner todos los medios a su alcance -riquezas, influencias, incluso rehenes- para rescatar a este hombre sabio de las garras de la muerte, los mismos medios con los que, en la época, se podía rescatar, por ejemplo, a los cautivos de guerra o del mar y que, de hecho, se emplearon, según cuenta la tradición ${ }^{18}$, para rescatar al ahora difunto R. Hušiel.

La imposibilidad de cumplir este deseo lleva a la aceptación de la desgracia, que ocurre «por orden de Dios».

En la sección dedicada al «duelo», asistimos a una descripción del intenso dolor y el abundante llanto que el conocimiento de tan luctuosa noticia produjo al autor de la carta; el propio texto bíblico presta las expresiones y figuras

\footnotetext{
${ }^{16}$ Un estudio pormenorizado sobre dicho género se puede encontrar en A. Navarro Peiro, El Tiempo y la Muerte: las elegías de Moseh ibn Ezra (Granada 1994).

17 Ver, por ejemplo, Navarro, El Tiempo y la Muerte, pág. 32

${ }^{18}$ Cf. supra y nota 3.
} 
literarias (hipérbole, metáfora o símil) que mejor sirven a la descripción: «se me derritió el corazón», «de mi cabeza brotaron aguas»; la convocatoria a la celebración del duelo aporta detalles sobre ritos y usos funerarios de la época, expresados en gran parte con imágenes bíblicas: «me rasgué las vestiduras», «convoqué una asamblea, decreté el ayuno y organicé el servicio fúnebre; compuse una elegía y nos presentamos con los hombros desnudos».

Una vez concluida la sección dedicada al llanto y al duelo, llega el momento de pronunciar palabras de consuelo para los allegados, y de entonar la alabanza del difunto; encontramos aquí la mención de nombres de lugares reales y cercanos al contexto histórico del relato: Granada, Lucena o Córdoba, junto a otros que evocan la tradición bíblica o rabínica: Raqqat o Babilonia.

El poema elegiaco, que ocupa el centro de la epístola, es parte integrante de la celebración del duelo; como ocurre en las macamas, en las que prosa rimada y poemas métricos se suceden, el poema es una especie de compendio y resumen de todo lo que la carta, en prosa rimada, expresa.

Entre los motivos habituales en este tipo de poemas ${ }^{19}$, resaltaremos los siguientes que encontramos en el que nos ocupa:

1. Duelo cósmico: la desgracia se extiende por todo el territorio: «en las provincias y en las aldeas», «en Ifriquiya [...] en Egipto y Sefarad», y va más allá: «el sol en oriente se ha quedado sin su luz», «la tierra está desolada y vacía», hay «oscuridad como de crepúsculo al mediodía».

2. El Tiempo es un enemigo poderoso y cruel que destroza «sin cuchillos ni garras» a fuertes y débiles.

3. En la alabanza del difunto se elogian determinadas cualidades, como la sabiduría, la rectitud y justicia, la piedad y generosidad; tenía «palabras que sanaban, sin médico, todos los males», era el «timonel» que dirigía a los marineros del barco; era «el mazo del Talmud» que disipaba las dudas.

4. La última parte de la elegía, dedicada al consuelo de los familiares, se transforma aquí en un panegírico dirigido al hijo; comienza con una expresión que resulta sorprendente: «Regocijaos»; la razón de este regocijo en medio de tanto duelo consiste, precisamente, en la existencia del destinatario de la carta, R. Hananel; la carta es, así, un consuelo para el hijo quien, a su vez, se transforma en el consolador de toda la comunidad. El hijo tiene las mismas cualidades del padre: generosidad, sabiduría, bondad y justicia, lo que le hace merecedor de ocupar el puesto que ha dejado vacante el difunto: «Estimado por ser maestro en su ley, es digno del rabinato, y éste digno de él», de esta manera, igual que su padre, él es

${ }^{19}$ Ver Navarro, El Tiempo y la Muerte, págs. 16-41

Sefarad, vol. 67:2, diciembre-junio 2007, págs. 311-325. ISSN 0037-0894 
ahora el agua del que bebe su pueblo - «el pueblo en Ifriquiya...de él bebe siempre»- y el alimento del que busca la instrucción.

La segunda parte de la epístola contiene palabras de consuelo para los deudos basadas en reflexiones de tipo sapiencial sobre la vida y la muerte y en nuevos elogios del difunto y de su hijo, al que se compara mediante distintas referencias alegóricas con destacados personajes bíblicos y rabínicos (R. Samuel, Moisés, David). Todos los que se ocupan en la Torá, a cuyo estudio él entregó su vida, son considerados sus hijos, y por tanto, hermanos entre sí, por lo que su muerte ha tenido, al final, un resultado positivo: todo el pueblo de Israel en el exilio se siente huérfano por la pérdida de R. Hušiel pero se siente acompañado en su dolor, y consolado por la gran legión de hermanos que ha dejado. La alabanza de la Torá da paso a una especie de autoelogio del autor por haber cumplido doblemente con el precepto de honrar a los muertos: «he llevado a tu padre en las exequias y he sido vehemente en su elegía», que va seguido de un requerimiento al destinatario para que dé pronta respuesta a la carta.

Concluye la epístola con unas palabras de despedida de tono más intimista y directo que el resto de la elegía, en las que Samuel ha-Naguid reitera el dolor que esta pérdida le ha causado.

Hemos seguido para nuestra traducción la edición de Dov Yarden ${ }^{20}$ para la carta en prosa, y la de Sáenz-Badillos y Targarona ${ }^{21}$ para la elegía incluida en ella. A continuación ofrecemos la traducción.

\section{TRADUCCIÓN}

Carta de pésame a nuestro maestro Hananel, descanse en paz, que se le hizo llegar de parte del maestro Samuel ha-Naguid ha-Leví, descanse en paz ${ }^{22}$.

A aquel cuyo esplendor es como el del hijo de Bityá ${ }^{23}$, por cuya causa se muestra favor para [toda] su generación ${ }^{24}$, nuestro querido maestro Ḥananel de parte de Samuel, el [más] pequeño de todos los sabios, mis saludos y condolencias.

\footnotetext{
${ }^{20}$ Yarden, Divan Shmuel HaNaguid, págs. 256-260.

${ }^{21}$ Sáenz-Badillos y Targarona Borrás, Semu'el ha-Naguid. Poemas. II, págs. 125*-127*.

${ }^{22}$ Se trata del título de la composición, escrito en árabe, y, a continuación, traducido al hebreo.

${ }^{23}$ Cf. 1 Cr 4, 18: los hijos de Bityá, hija del faraón; según Sanh 31b, se refiere a Moisés. Cf. Sanh $19 \mathrm{~b}$

${ }^{24}$ Cf. Hag 14a: «Un hombre de rango (Is 3,3), esto significa uno por cuya causa se muestra favor para [toda] su generación»; esta es una de las citas rabínicas que Ibn Nagrella traduce al arameo. Ver supra n.14.
} 
He de informar a [mi] señor de que, aunque su suerte se quebrara y el tiempo arrojara sobre él su red, haciendo sus dolores semejantes al mar ${ }^{25}$, cuando su ancianidad fue reclamada por la Academia Celestial, no sólo a él le fue arrancada la lámpara, apagada la luz, desordenada la mesa, y pisoteado [el altar], sino [también] a todos los habitantes de la tierra que habitan bajo todo el cielo ${ }^{26}$, pues todos ellos saben que una desgracia ha sacudido al mundo ${ }^{27}, \mathrm{y}$ que, cuando muere un sabio, todos son sus parientes ${ }^{28}$, cuanto más nosotros, los hijos de la Torá: la túnica de fiesta se ha ocultado de nuestra vista, se ha escondido la perla, ha caído de nuestra cabeza la corona ${ }^{29}$, se ha apartado de nosotros la belleza y nos hemos quedado sin el hombre que ha sido entregado por nuestros pecados al polvo.

Y si pudiera volver a la vida, yo intentaría rescatarlo con un gran tesoro de perlas, rubíes y topacios ${ }^{30}$, y justificando mi lamento, enriquecería a médicos, daría riquezas y entregaría en su lugar a pueblos [enteros], según está escrito: Más que Ǎ̌šr eres valioso a mis ojos, eres estimado [y te amo, y entregaré a Edom en lugar tuyo, y pueblos en lugar de tu persona] ${ }^{31}$. Pero ¿qué le vamos a hacer? Es por orden del Dios de los cielos y decreto del Señor, el Altísimo, según está escrito: Nadie puede en modo alguno redimir a otro, ni satisfacer a Elohim su rescate ${ }^{32}$. El Grande y Poderoso ${ }^{33}$ sabe que, cuando escuché la noticia y se me informó de su fallecimiento, se me derritió el corazón, desfa-

${ }^{25}$ Cf. La 2,13: Pues grande como el mar es tu quebranto.

${ }^{26} \mathrm{Da} 7,27$.

27 Sanh 113b: «Cuando un justo parte de este mundo, el mal viene al mundo», comentando Is 57,1 .

28 Šabb 105b y $M Q 25$ : «Cuando muere un sabio, todo el mundo es su pariente. ¿Todo el mundo es su pariente? ¿Cómo se te ocurre? Digamos más bien "todo el mundo es como si fuera su pariente”, todos tienen que rasgarse [la ropa] por él, todos tienen que descubrirse los hombros por él...».

${ }^{29}$ Cf. La 5,16: Ha caído la corona de nuestra cabeza.

${ }^{30}$ Además de referirse al valor real de estas piedras preciosas, parece haber también una referencia al pectoral del sumo sacerdote (Cf. Ex 28,17: Una fila de una coralina, un topacio y una esmeralda será la primera fila). Se trata de piedras de identificación insegura; así, el «rubí», es para otros el «carbunclo»; el «brillante» sería el «diamante» y el «jaspe», y el «ónice», el «berilo», «diaspro»o «jaspe». Sobre los nombres de las piedras del pectoral en las distintas versiones y en el midrás, $c f$. W. BACHER, «Une ancienne liste des noms grecs des pierres précieuses relatées dans Exode XXVIII» REJ 29 (1894) págs. 79-90; S. Lieberman, Greek in Jewish Palestine (New York 1965) págs. 56-59.

${ }^{31}$ Is 43,4 .

32 Sal 49,8 .

${ }^{33}$ Cf. De 10,17: Grande, poderoso y terrible. 
lleció mi espíritu, se me estremecieron las caderas ${ }^{34}$, de mi cabeza brotaron aguas y mis ojos derramaron lágrimas ${ }^{35}$. Rasgué mis vestiduras, reuní a mi comunidad, hablé de sus cosas ${ }^{36}$, informé de su gloria a quien no le había conocido, proclamé su alabanza a quien no la había escuchado, y clamé por él: «Nuestro maestro era merecedor de que la Šejiná se posara sobre él, pero Babilonia lo impidió» ${ }^{37}$. Y alcé la voz diciendo: «Tú mismo, maestro Ḥušiel, en territorio impuro morirás ${ }^{38}$; todos nosotros sabemos y conocemos que se ha roto el compromiso ${ }^{39} \mathrm{y}$ el pueblo de Israel se ha quedado [sin un gran hombre] [...]» ${ }^{40}$; entonces convoqué una asamblea, decreté el ayuno y organicé el servicio fúnebre $[\ldots]^{41}$; compuse esta elegía, y nos presentamos con los hombros desnudos ${ }^{42}$. [Comencé] a hablar en primer lugar, igual que había hecho [cuando murió mi padre] [anteriormente], y como R. Judá dijo que había dicho Rab: «Los consoladores ${ }^{43}$ no están autorizados a decir nada hasta que haya empezado, en primer lugar, el plañidero, pues está dicho: Sin que ninguno le hablara palabra, pues veían que el dolor era muy grande ${ }^{44}$. Después de esto abrió Job su boca ${ }^{45}$ ». Y pronuncié estas palabras: "iAy del humilde, ay del piadoso ${ }^{46}$, ay del grande en Ifriquiya cuya fama llegaba a Raqqat! ${ }^{47} \gg$. E igual

${ }^{34}$ Cf. Je 6,24: Al oír la nueva, desmayaron nuestros brazos; Neh 2,11 corazones derretidos de pavor y temblor de rodillas, y estremecimiento en todos los lomos.

${ }^{35}$ Cf. Je 8,23: ¿Quién quiera que mi cabeza fuese agua y mis ojos fuente de lágrimas!

${ }^{36}$ Cf. Ber 3b: «No se puede hablar en presencia de un muerto más que de cosas relacionadas con el fallecido».

${ }^{37} M Q 25 \mathrm{a}$

${ }^{38}$ Cf. Ket 111a: «Tú mismo, Ulla, morirás en territorio impuro». Cf. Am 7,17: Tú mismo morirás en territorio impuro.

${ }^{39}$ AZ 10b. Fórmula que se pronuncia cuando se produce el fallecimiento de un ser muy querido.

${ }^{40}$ Hay una laguna en el texto.

${ }^{41}$ Hay una laguna en el texto.

${ }^{42}$ Cf. BQ 17a: «Y ellos le honraron a su muerte (2Cr 32,33), en el caso de Ezequías, rey de Judá, significa que salieron ante él treinta y seis mil [guerreros] con los hombros desnudos». Los «hombros desnudos» eran una señal de lamento por el fallecimiento de un hombre justo y sabio.

${ }^{43} M Q 28 \mathrm{~b}$, puesto en boca de R. Yojanán.

$44 \mathrm{Jb} 2,13$.

$45 \mathrm{Jb} 3,1$; cf. MQ 28b: «dijo R. Judá... abrió Job su boca».

${ }^{46}$ Ber 6b. Lit.: «¡Dónde está el humilde! ¡Dónde está el piadoso!».

${ }^{47}$ Cf. Meg 6a. «¿Hay alguien que mantenga que Raqqat no es Tiberias, considerando que cuando un hombre muere aquí [en Babilonia], se lamentan por él allí [en Tiberias] así: "Grande era él en Šešaj [Babilonia], y tenía fama en Raqqat [Tiberias]”?». 
que me ocupé de su elegía en Granada, también me he ocupado en Lucena; preparé lecturas ${ }^{48}$ y mandé a distinguidos emisarios a Córdoba y a otras muchas de aquellas ciudades [fortificadas], y en todas ellas se hizo lo mismo que yo había hecho. Y claramente mencioné que se había enfadado el pastor con su rebaño ${ }^{49}$, se había enfurecido el rey contra su pueblo ${ }^{50}$, como está escrito: El justo perece, mas nadie hay que pare mientes ${ }^{51}$; también mencionamos en aquellas elegías: «[Dios] se enfada con el mundo y arrebata almas con las que se alegra como una nueva novia; el que cabalga en las nubes se regocija y se alegra al llegar ante él un alma limpia y justa $\left.{ }^{52}\right\rangle$. Y debido a nuestras numerosas aflicciones he compuesto estas breves palabras y las he enviado a [mi] señor:

¿Qué es ese pesar tan grande en las provincias y aldeas, que todos entonan endechas?

No es voz de cantos de victoria ni es voz de cantos de derrota ${ }^{53}$

¿Qué es ese desconcierto tan grande en Ifriquiya, que se resienten Egipto y Sefarad ${ }^{54}$ ?

El Tiempo, sin cuchillos ni garras, ha desgarrado a este león como a un cabrito ${ }^{55}$.

5 ¿Cómo puede alcanzar la enfermedad a aquel cuyas palabras sanaban, sin médico, todos los males?

¿Cómo, sin martillo, el hombro se nos ha desgajado de la espalda como si fuera un junco ${ }^{56}$ ?

48 Lit.: «lecturas o composiciones introductorias, proemios».

49 Cf. BQ 52a: «Cuando el pastor se enfada con su rebaño, nombra como guía a un ciego».

50 Cf. Is 47,6: Me había enfurecido contra mi pueblo.

${ }^{51}$ Is 57,1 .

${ }^{52} M Q 25 b$.

${ }^{53}$ Lit.: «No es sonido de vencedores en la tropa, tampoco sonido de derrotados en las filas»; parece que el autor hace una versión del texto bíblico Ex 32,18, que por su mejor adecuación al contexto mantenemos.

54 Lit.: «Memfis e Hispania».

${ }^{5}$ Cf. Jue 14,5-6: Un león joven salió rugiendo a su encuentro... y lo despedazó como se despedazaría un cabrito, sin que tuviera nada en la mano; cf. TgJ: «Y he aquí que un león, hijo de leones, ruge ante él... y lo despedazó como despedazarían un cabrito, sin nada en sus manos».

56 Tal vez se refiera al hueso «húmero», como en $\mathrm{Jb}$ 31,32: ;Mi espalda de su nuca se desprenda, y mi brazo de su húmero se desgaje!. 
¡Vosotros que bebíais el vino en copas! ${ }^{57}$, ha llegado el mal que sin vino os emborracha ${ }^{58}$.

El sol en oriente se ha quedado sin su luz, pues en occidente ha llegado al ocaso su compañero.

Ha sido destruido el timonel ${ }^{59}$, y los marineros del barco se parecen a los gallos de Bet Buqyá ${ }^{60}$.

10 Se ha quebrado el mazo del Talmud,

ha enfermado gravemente, nadie resuelve, siguen las dudas.

Desaparecieron las casias ${ }^{61}$ y los perfumes, se muda el costo ${ }^{62}$ aromático muy puro.

Venían para debatir sobre temas evidentes mientras continuaba girando la rueda del molino ${ }^{63}$.

$[\ldots]$ palmera $[\ldots]^{64}$ un árbol ha dejado un plantón en tierra de regadío.

$[\ldots]^{65}$ La tierra estaba desolada y vacía ${ }^{66}$.

$15[\ldots]^{67}$ oscuridad al mediodía como el crepúsculo.

${ }^{57}$ Cf. Am 6,6: que beben el vino en copas. En $T g J$ : «Los que beben en copas de plata vino».

${ }_{58}$ Cf. Is 51,21: ;Ebria, pero no de vino!; cf. TgJ: «iQue estás ebria de calamidad, pero no de vino!».

${ }^{59} C f$. BB 91a-b: «En el día que Abraham, nuestro padre, partió de este mundo, todos los grandes de las naciones se pusieron en fila y dijeron: “¡Ay del mundo que ha perdido su guía!

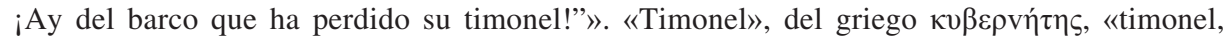
piloto».

${ }^{60}$ Es decir, alborotados y peleando entre sí. Cf. Yeb 84a: «Dijo Rabbí "Cuando fui a aprender la Torá a [la escuela de] R. Eleazar b. Šammúa, sus discípulos se unieron contra mí como los gallos de Bet Buqyá"». «Bet Buqyá» es una ciudad en la Alta Galilea, conocida por sus gallos de pelea, que no se podían mezclar con gallos de otras procedencias.

61 «Casias», canela, corteza de las ramas del canelo. Cf. Real Academia Española [RAE], Diccionario de la lengua española (21 ${ }^{\text {a }}$ ed. Madrid 1992).

62 «Costo», hierba vivaz, propia de la zona tropical, y correspondiente a la familia de las compuestas.... $C f$. RAE, Diccionario.

${ }^{63}$ Cf. Sanh 24a.

${ }^{64}$ Hay varias lagunas en el texto.

${ }^{65}$ Hay una laguna en el texto.

${ }^{66}$ Gen 1,2: La tierra era yermo y vacío; TgOnq: «La tierra estaba desolada y vacía».

${ }^{67}$ Hay una laguna en el texto. 
$[\ldots]^{68}$

Regocijaos, que, aunque ha muerto un león, otro se alza.

Un hombre, que a todo el que busca instrucción ${ }^{69}$

sacia con los dátiles que hay en la esterilla ${ }^{70}$.

Le plantean cuestiones, y todo cuanto le plantean

lo resuelve, se hace cargo de las dificultades.

Está presto a aplicar justicia ${ }^{71}$, se ciñe la

verdad como quien se ciñe un cinto ${ }^{72}$.

20 Expresa las opiniones discrepantes

sobre la Halajá que se enseña oficialmente.

Explica todas las objeciones, soluciona

los contrasentidos y resuelve las incógnitas.

Estimado por ser maestro en su ley, es digno del rabinato, y éste digno de él.

Limpia las semillas como la lluvia ${ }^{73}$, conduce a sus discípulos como el pastor ${ }^{74}$.

El pueblo en Ifriquiya, en el nacimiento del río mora, y de él bebe siempre que lo desea.

25 Se alimentan de la instrucción sin pagar un precio ${ }^{75}$

68 Hay una laguna en el texto.

69 Cf. Ex 33,7: Y sucedió que todo el que quería consultar a Yahveh...; cf. TgOnq: «Todo el que buscaba instrucción...».

70 Cf. Ket 50b: «Dale a ella de los dátiles que hay sobre la esterilla».

71 Cf. Is 16,5: presto a la justicia.

${ }^{72}$ Cf. Is 11,5: Y será la justicia el ceñidor de sus lomos, y la verdad el cinturón de sus caderas. El hombre sabio se caracteriza por la virtud y la justicia, y no por la violencia o el poder físico, que queda simbolizado en el cinturón del guerrero; $c f$. Is 3,24: en lugar de cinturón; cf. TgJ «en el lugar que ellos acostumbraban a ceñir sus cinturones».

73 Cf. Ta'a 3b-4a: «La nieve es beneficiosa para las montañas, las fuertes lluvias para los árboles, la lluvia suave para los frutos del campo, la llovizna incluso para las semillas debajo de la tierra dura... Rabbá también dijo: Un joven rabino se parece a la semilla debajo de la tierra dura; una vez que ha brotado, se dispara hacia arriba».

${ }^{74}$ Cf. Is 40,11: Como un pastor pastorea su rebaño, con su brazo lo reúne; a los corderillos lleva en su regazo; $c f$. TgJ: «Como un pastor que pastorea su rebaño, reúne a los corderos con su brazo, y lleva a los corderillos en su regazo».

75 Cf. Is 55,1: ¡Ay sedientos todos, acudid a las aguas, incluso el que no tenga dinero! ;Venid! ¡Comprad y comed, y andad, comprad sin dinero y sin precio vino y leche!; cf. TgJ « ¿Ay todo el que quiere aprender, que venga y aprenda, incluso el que no tenga dinero! ¡Que vengan, escuchen y aprendan! ¡Venid, escuchad y aprended, sin precio y sin dinero, la ley, pues es mejor que el vino y la leche!». 
¡dichoso aquel que la encuentra con dinero!

¡Sólo el que coge en sus manos la colmena

es el que saca todo lo dulce!

Y para concluir todo este discurso diremos sobre él lo mismo que dijeron los justos y los ángeles del servicio: Entrará en la paz, reposarán sobre sus lechos ${ }^{76}$. Y por nuestro maestro Hananel [hay que] despojarse del luto y vencer el dolor ${ }^{77}$, pues el final de todo hombre es morir, y todos estamos condenados a la muerte ¡Dichoso aquel cuyo trabajo ha sido la Torá y ha causado satisfacción a su Creador, que ha crecido con un buen nombre y se marcha de este mundo con buen nombre ${ }^{78}$ ! ¿Dichoso tú [nuestro maestro] Hušiel, que has fallecido pero has dejado tu memoria en un hijo muy sabio ${ }^{79}$, perfección de la Torá, brasa ${ }^{80}$ [siempre encendida] del Talmud, Aryoj ${ }^{81}$ y rey Sapor ${ }^{82}$, Sinay y demoledor de montañas ${ }^{83}$ de esta generación; te pareces al primer profeta que

${ }^{76}$ Cf. Ket 104a: «Cuando un hombre justo parte de este mundo, los ángeles del servicio dicen ante el Santo, bendito sea: ¡Señor del universo, Fulano, el justo, viene! Él les contesta: ¡Que vengan los justos! ¡Que salgan a su encuentro!, y decidle: "Entrará en la paz, reposarán sobre sus lechos" (Is 57,2)».

77 Lit.: «aceptar el consuelo».

${ }^{78}$ Cf. Ber 17a: «El final del hombre es morir, y el final de la bestia es el matadero; todos están condenados a morir. ¡Dichoso aquel que ha crecido con la Torá y cuyo trabajo está en la Torá, que ha causado satisfacción a su creador, y que ha crecido con un buen nombre y se marcha de este mundo con un buen nombre!»

${ }^{79}$ Lit.: «hijo de maestro».

80 שיחורא, lit. «carbón, brasa». Es posible también pensar en שחוור, oficial», o relacionar el término con la raíz שחר, «buscar, investigar», y de ahí el posible sentido de «investigador, erudito»"

${ }^{81} C f$. Šabb 53a: «Y así también explicó Aryoj en Babilonia. Pero ¿quién es Aryoj? ¡Samuel!»; "Aryoj», se trata de un sobrenombre de Samuel, el contemporáneo de Rab; según Jastrow sería una adaptación del término persa para «juez» ( $c f$. M. JASTROw, A Dictionary of the Targumim, the Talmud Babli and Yerushalmi, and the Midrashic Literature (New York 1943) pág. 119); otros aluden a אִ, o al griego ä $\rho \chi 0 \varsigma$, «rey» (cf. J. Levy, Wörterbuch über die Talmudim und Midraschim [Berlin und Wien 1924] pág. 165).

${ }^{82}$ Sapor I, rey de Persia, fue conocido por su amistad con Samuel, el contemporáneo de Rab; en el Talmud se refieren, con frecuencia, a Samuel con el nombre de Sapor; $c f$. BB 115b. «Rabbá dijo: Puedo decir algo que el rey Sapor no pudo haber dicho. Pero, ¿quién es él? Samuel».

${ }^{83}$ Cf. Ber 64a: «R. Yosef era Sinay, y Rabbá era un demoledor de montañas». «Sinay» es un calificativo que indica un conocimiento enciclopédico de las tradiciones; «demoledor de montañas» indica una persona erudita muy hábil en la dialéctica. 
equivale a $600.000^{84}$. El que pueda engendrar a alguien como él, [que lo haga], $\mathrm{y}$, si no, que no engendre ${ }^{85}$, y el que se va [al otro mundo] y deja a alguien como él - [en realidad] no se ha ido ${ }^{86}$; cuanto más, los justos como él, a los que protege el palio ${ }^{87}$ del crepúsculo, y se les cría un hijo antes de que se haya despedido el padre, como dijeron allí: Antes de que se extinguiera el sol de Elí, brilló el sol de Samuel de Ramot ${ }^{88}$. Y después de esto yo digo a [mi] señor que ha sido revelado ante los cielos [...] para hablar [...], y debido a los exilios que nos abrumaron, y los pesares del cielo [...] con los dones del estudio, y no me he encariñado con [...] los sabios de Babel y toda la tierra de Israel] [...] juntos. ${ }^{89} \mathrm{Y}$ con más razón me resulta evidente que se trata de un gran hombre, único en Occidente.

Y desde ahora, por dos motivos podemos ser considerados como hermanos y semejantes a hijos de un mismo padre ${ }^{90}$ : uno es la relación con la Torá, en la que nos ocupamos y en la que se centra nuestro trabajo ${ }^{91}$, y puesto que ella misma es nuestra hermana, también nosotros somos hermanos, como está escrito: $D i$ a la Sabiduría: «Tú eres mi hermana» y llama «pariente» a la Inteligencia ${ }^{92}$; y el otro [motivo] es que en verdad he llevado a su padre en las exequias, y he sido vehemente en su elegía ${ }^{93}, y$ me resulta claro que todo el que haya estado presente en sus exequias, está destinado [a gozar de] la vida del otro mundo ${ }^{94}$. Por estos dos [motivos], solicito yo de mi señor que no se retrase su carta ni se

${ }^{84}$ Se refiere a Moisés; $c f$. LevR 1,3: «[A Moisés se le llamó] "Padre de Sôkô” porque era el padre de los profetas que veían [sôk̂im] por medio del Espíritu Santo. R. Leví dijo: "Se trata de una palabra árabe; en lengua árabe a un profeta se le denomina sakya”»; cf. CantR 1, 15.3.1: «se trata de Yojébed que parió a Moisés al que se valora como seiscientos mil, que son los israelitas»; $c f . N u$ 11,21.

${ }^{85}$ Cf. Mak 17b: «¡Ojalá que toda mujer embarazada tuviera un niño como R. Simón, y si no [puede ser como él], que no conciba!».

${ }^{86} C f$. $B B$ 116a: «[En el caso de] David, que dejó un hijo como él, se utiliza [la expresión de] שכיבה [«acción de estar acostado, tumbado»]; [en el caso de] Joab, que no dejó un hijo como él, se usa [el término] מיתה [《muerte»]».

${ }^{87} C$ f. BB 75a: «El Santo, bendito sea, hará siete ḥuppôt ("dosel”) para todo hombre justo».

${ }^{88}$ Qid 72b; cf. Qo 1,5: Sale el sol y el sol se pone.

${ }^{89}$ «Y después de esto... juntos». Se trata de un párrafo con muchas lagunas, y de muy difícil interpretación.

${ }^{90}$ Lit.: «hijos de padre pariente».

${ }^{91}$ Cf. Ber 17a, «Dichoso aquel cuyo trabajo está en la Torá».

92 Cf. Prov 7,4 .

${ }^{93} C f$. $\breve{S} a b b$ 153a: «Sé vehemente en mi elegía». Si despierta una pena muy extendida, se debe tratar de un buen hombre que ha ganado el disfrute del otro mundo.

${ }^{4}$ Cf. Ket 103b: «Todo el que haya estado presente en el réquiem de Rabbí está destinado [a gozar de] la vida del otro mundo».

Sefarad, vol. 67:2, diciembre-junio 2007, págs. 311-325. ISSN 0037-0894 
demore su respuesta, informando de su salud y de la salud de su Torá, de sus sabios compañeros y de sus inteligentes discípulos. Y debido a que he escrito esta carta en medio del desasosiego, con el espíritu perturbado, el entendimiento desfallecido, y el corazón enfermo por estas penas que nos han cercado hasta el extremo de que el tonto no se siente molestado, ni la carne del muerto nota el escalpelo ${ }^{95}$, por esto, me he dirigido a mi señor con un breve discurso y una insignificante alabanza. Y cuando sepa mi señor que la oración de los devotos es mucho más eficaz en los cielos, entonces estará obligado a pedir sobre nosotros misericordia, como dijeron: "Todo aquel al que le haya sucedido una calamidad...» ${ }^{96}$, y como está escrito: Abraham rogó a Ha-Elohim, y Elohim sanó a Abimélej... ${ }^{97}$

Paz eterna sobre Jerusalén. Samuel ha-Leví ben R. Yosef ¡que en gloria esté!

RESUMEN

En el presente artículo ofrecemos la traducción y el estudio de la carta de pésame enviada por Samuel ha-Naguid a R. Ḥananel b. Hušsiel por la muerte de R. Ḥušiel b. Elḥanán, su padre.

PALABRAS ClaVE: Samuel ha-Naguid; arameo; carta de pésame.

\section{SUMMARY}

In this article we offer a Spanish translation with a commentary of an Aramaic letter of consolation written by Samuel ha-Naguid and sent to R. Hananel b. Hušiel, lamenting the death of R. Hušiel b. Elḥanan, his father.

KeYwords: Samuel ha-Naguid; Aramaic; Letter of Consolation.

\footnotetext{
${ }^{95} C f . \breve{S} a b b$ 13b: «Un tonto no es molestado, ni la carne del muerto siente el escalpelo».

96 Cf. Sot 32b: «A todo aquel que le haya sucedido una calamidad, debe decírselo a mucha gente, para que esa gente ruegue misericordia por él».

${ }^{97} B Q$ 92a: «¿De dónde viene la lección enseñada por nuestros rabinos de que uno que ruega misericordia para su compañero, cuando él necesita también lo mismo, se le responde primero?... Porque está escrito: Abraham rogó a Ha-Elohim, y Elohim sanó a Abimélej su mujer y sus siervas... (Ge 20,17), e inmediatamente después está escrito: Yahveh visitó a Sara, como él había dicho... (Ge 21,1), [es decir] como Abraham había [rogado] y dicho en atención a Abimélej».
} 